\title{
Oxidative Modifications of RNA and Its Potential Roles in Biosystem
}

\author{
Mikiei Tanaka* and P. Boon Chock \\ Biochemistry and Biophysics Center, National Heart Lung and Blood Institute, National Institutes of Health, Bethesda, MD, \\ United States
}

Elevated level of oxidized RNA was detected in vulnerable neurons in Alzheimer patients. Subsequently, several diseases and pathological conditions were reported to be associated with RNA oxidation. In addition to several oxidized derivatives, cross-linking and unique strand breaks are generated by RNA oxidation. With a premise that dysfunctional RNA mediated by oxidation is the pathogenetic molecular mechanism, intensive investigations have revealed the mechanism for translation errors, including premature termination, which gives rise to aberrant polypeptides. To this end, we and others revealed that mRNA oxidation could compromise its translational activity and fidelity. Under certain conditions, oxidized RNA can also induce several signaling pathways, to mediate inflammatory response and induce apoptosis. In this review, we focus on the oxidative modification of RNA and its resulting effect on protein synthesis as well as cell signaling. In addition, we will also discuss the potential roles of enzymatic oxidative modification of RNA in mediating cellular effects.

\section{OPEN ACCESS}

Edited by: Norbert Polacek, University of Bern, Switzerland

Reviewed by:

Michael Ibba,

Chapman University, United States Matthias Erlacher,

Medical University of Innsbruck, Austria

*Correspondence: Mikiei Tanaka mikiei.tanaka@nih.gov

Specialty section: This article was submitted to Protein and RNA Networks, a section of the journal Frontiers in Molecular Biosciences

Received: 25 March 2021 Accepted: 27 April 2021 Published: 12 May 2021

Citation:

Tanaka M and Chock PB (2021) Oxidative Modifications of RNA and lts

Potential Roles in Biosystem. Front. Mol. Biosci. 8:685331. doi: 10.3389/fmolb.2021.685331
Keywords: translation error, oxidative stress, 8-oxoguanine, abasic site, apoptosis, signal transduction pathway, cross-link, inflammation

\section{INTRODUCTION}

Reactive oxygen species (ROS) and free radicals play major roles in normal biological functions. However, they can also react rapidly with biomacromolecules, such as nucleic acids, proteins, or lipids, and alter their biological functions. Therefore, they have been implicated in a wide range of age-related neurodegenerative diseases and aging (See (Stadtman and Berlett, 1997; Beckman and Ames, 1998; Thannickal and Fanburg, 2000) for Rev.). With respect to nucleic acid oxidation, DNA is known to be protected by its binding proteins, and by a number of repair systems to minimize its damaging effects (Evans et al., 2004). However, RNAs are reportedly more susceptible to oxidation than DNA (Hofer et al., 2005). As a result, age-related diseases would be more likely to be associated with RNA oxidation. Consistent with this notion, an elevated level of oxidized RNA was found in Alzheimer's disease (AD) (Nunomura et al., 1999), and Parkinson's disease (PD) (Zhang et al., 1999).

Abbreviations: AD, Alzheimer's disease; A, adenosine; ALS, amyotrophic lateral sclerosis; APE1, apurinic/apyrimidinic endonuclease1; AP site, apurinic/apyrimidinic site; ARP, aldehyde reactive probe; Cyt c, cytochrome c; C, cytidine; EGFP, enhanced green fluorescent protein; $\mathrm{G}$, guanosine; $\mathrm{H} 2 \mathrm{U}$, 4-pyrimidinone ribofuranoside; $\mathrm{MPG}$, methylpurine DNA glycosylase; mtRNA, mitochondrial RNA; NLRP3, (NOD)-like receptor protein 3; RIP, ribosome inactivating protein; PAP, pokeweed antiviral protein; PARP-1, poly(ADP-ribose) polymerase 1; PCBP, poly(C) binding protein; PD, Parkinson's disease; PMA, phorbol myristate acetate; PNPase, polynucleotide phosphorylase1; PTC, Peptidyl Transferase Center; sGC, soluble guanylyl cyclase; ROS, reactive oxygen species; S2U, 2-thiouridine; U, uridine; 8-oxo-G, 8-oxo-7,8-dihydro-guanosine; 8-oxo-dG, 8-oxo7,8-dihydro-deoxyguanosine; 8-oxo-A, 8-oxo-7,8-dihydro-adenosine. 
Consequently, research on RNA oxidation has been directed toward understanding the potential mechanisms by which oxidized RNA mediates age-related diseases. To date, elevated oxidation of RNA, monitored by the formation of 8-oxo-7,8dihydroguanosine (8-oxo-G), has been reported in a variety of diseases such as diabetes (Cejvanovic et al., 2018), schizophrenia (Jorgensen et al., 2013), and depression (Jorgensen et al., 2013). The fact that 8-oxo-G rather than 8-oxo-7,8dihydroxydeoxyguanosine (8-oxo-dG) was found elevated in the urine or plasma of disease patients, suggests that the disease is associated with the elevation of RNA oxidation. Therefore, monitoring the extent of RNA oxidation via its oxidative stress biomarker provides a useful method for diagnosing age related diseases (see review (Poulsen et al., 2012; Jacob et al., 2013; Larsen et al., 2019)). However, the molecular analysis of RNA oxidative modifications and cellular responses have not been fully investigated. Based on DNA oxidation studies (Lindahl, 1993), 8-oxo-G and abasic site, which is the ribose moiety after depurination/ depyrimidination, are most likely to be the predominant oxidative derivative of ribonucleosides. In addition, RNA oxidation could lead to the formation of cross-linking with proteins and a strand scission. From the pathogenetic point of view, we and others have reported the effects on translational activity mediated by the oxidation of tRNA (Preiss et al., 1959; Sochacka et al., 2015), mRNA (Shan et al., 2007; Tanaka et al., 2007; Calabretta et al., 2015; Thomas et al., 2019), and rRNA (Honda et al., 2005; Willi et al., 2018). The decrease in translational activity is due to the accumulation of aberrant polypeptides caused by premature termination and amino acid misincorporation. Together, these could constitute a pathogenic mechanism, since accumulation of abnormal proteins is known to disrupt protein homeostasis, a phenomenon observed in many pathological features in diseases (Hipp et al., 2014). On the other hand, recent extensive research on the RNA quality control systems revealed that dysfunctional mRNA including oxidized mRNA, in which ribosomes are stalled or collided would be eliminated together with nascent polypeptides by a set of proteins including endoribonuclease and ubiquitin ligase (see review (Ikeuchi et al., 2018; Collart and Weiss, 2020)). However, the regulatory mechanisms mediated by oxidized RNA per se are not fully investigated.

ROS are known to be involved in mediating cell signaling (Rhee, 2006; Bochkov et al., 2010; Alenko et al., 2017; Lanz et al., 2019; Sengupta et al., 2020). In line with this notion, it has been reported that oxidatively modified RNAs could interact with various biological molecules known to mediate cell signaling. In addition to the negative impacts caused by compromising the RNA biological functions, RNA oxidation could also modulate certain cell signaling pathways. Evidence has emerged showing the products of RNA oxidation, e.g. 8-oxo-G as well as 8-oxo-dG could exhibit an antioxidant function (Lee et al., 2013). In addition, 8-oxo-GTP has been reported to modulate G-protein GTPase activity (Yoon et al., 2005) and soluble guanylyl cyclase (Bolin and Cardozo-Pelaez, 2009). Furthermore, oxidation of mitochondrial RNA could modulate the inflammatory response through cytokine induction (Saxena et al., 2017).
RNA containing the 8 -oxo-G could modulate an apoptotic signaling pathway mediated by the oxidized RNA's binding proteins (Ishii et al., 2020). In addition, an oxidatively modified microRNA such as miR-184 has been shown to mediate cellular apoptosis via its interaction with the 3-UTR region of Bcl-xL and Bcl-w (Wang et al., 2015), and processing of miRNAs such as miR-221 has been shown to be regulated via oxidative modification and the apurinic/apyrimidinic endoribonuclease1 (APE1) (Antoniali et al., 2017). We have shown that cytochrome $c$ (cyt $c$ ) could form a cross-linked complex with oxidized RNA, and facilitate its dissociation from mitochondria to the cytosol, a process required to initiate the mitochondria-mediated apoptosis. Our findings imply that oxidative modification of RNA facilitates cellular apoptosis via a protective signal in response to oxidative stress (Tanaka et al., 2012). In addition, in this review, we will also describe other possible roles of enzyme-catalyzed, oxidation-like modifications of RNA. In this case, the formation of the RNA abasic site is catalyzed by an N-glycosylase which in turn is processed by APE1 in the R-loop region to modulate DNA replication or transcription possibly (Liu et al., 2020). Pokeweed antiviral protein initiates an antiviral defense by abasic formation of viral RNAs (Di and Tumer, 2015). As illustrated in Figure 1, oxidized RNA could exert extensive biological functions, a subject that needs further investigation.

\section{RNA OXIDATIVE MODIFICATIONS}

Among endogenous ROS, superoxide anions and $\mathrm{H}_{2} \mathrm{O}_{2}$ are ubiquitously generated from the electron transport chain (Boveris and Chance, 1973; Boveris and Cadenas, 1975). A superoxide anion is converted to $\mathrm{H}_{2} \mathrm{O}_{2}$ in a reaction catalyzed by superoxide dismutase. While the reactivity of both the superoxide anion and $\mathrm{H}_{2} \mathrm{O}_{2}$ are relatively mild, in the presence of metal ion such as $\mathrm{Fe}(\mathrm{II}), \mathrm{H}_{2} \mathrm{O}_{2}$ is converted to hydroxyl radical, which is a highly reactive ROS (Goldstein et al., 1993; Wardman and Candeias, 1996). This metal ion catalyzed hydroxyl radicals generation is known as the Fenton reaction, a reaction thought to be the most pathophysiologically relevant in mediating RNA oxidation (Nunomura et al., 1999; Honda et al., 2005). Since RNA contains multiple high affinity binding sites for iron, some of these irons are likely to bind to the $\mathrm{Mg}$ (II) binding sites (Berens et al., 1998; Athavale et al., 2012; Zinskie et al., 2018). Hereafter, we primarily consider the RNA oxidation proceeds via iron mediated Fenton reaction.

\section{8-0xo-G}

To our knowledge, the first investigation to quantify 8-oxo-G as a RNA oxidative derivative was reported in 1989 (Fiala et al., 1989). 8-oxo-G in rat liver RNA was elevated by treatment with a hepatocarcinogen, 2-nitropropane. It has been generally thought that 8 -oxo-G is the most abundant oxidative derivative in RNA oxidation. In addition, there have been several assays developed to quantify 8-oxo-G: 1) highperformance liquid chromatography coupled with an electrochemical potential detector (Floyd et al., 1986; 


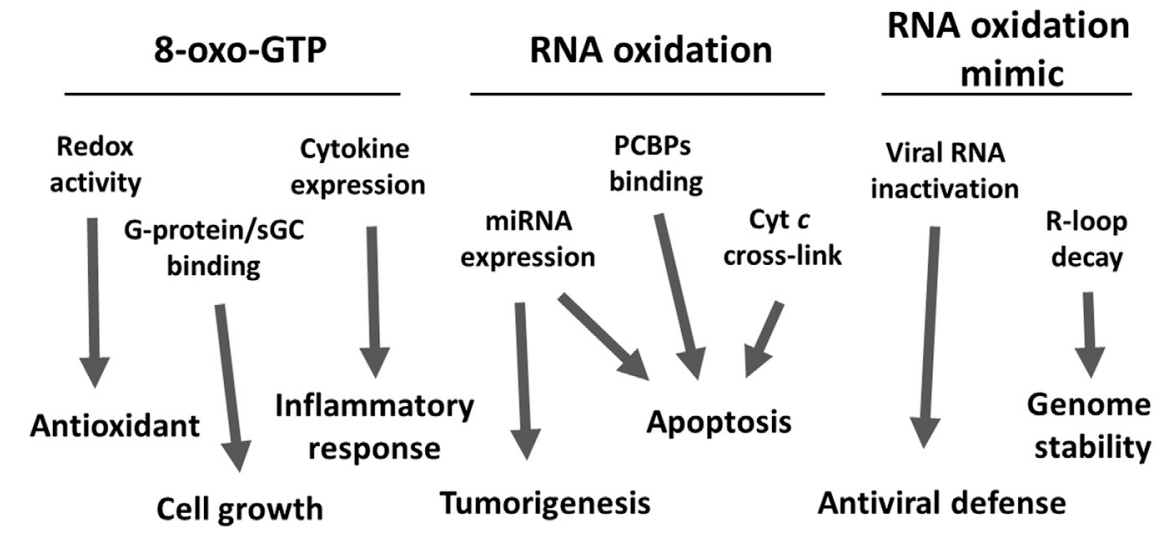

FIGURE 1 | A schematic diagram of the potential roles of oxidized RNA. Three types of oxidized RNA, free 8-oxo-GTP, oxidized RNA, and the equivalently modified RNA modulate several cellular functions and signaling pathways. The possible effects of those modulations, but not limited to are also represented. The detailed mechanisms are described in the text.<smiles>NC1=NC(n2c(=O)[nH]c3c(=O)[nH]c(N)cc32)=C(O)[C@H]1O</smiles>

8-0xo-G<smiles>OCC1O[C@@H](O)[C@H](O)[C@H]1O</smiles><smiles>C=C=C</smiles><smiles>O=c1ccn(C2OC(CO)C(O)C2O)cn1</smiles>

$\mathrm{H} 2 \mathrm{U}$

FIGURE 2 |Chemical structures of the representative oxidative derivatives. 8-oxo-G (8-oxo-7,8-dihydro-guanosine), 8-oxo-A (8-oxo-7,8-dihydro-adenosine), $\mathrm{H} 2 \mathrm{U}$ (4-pyrimidinone ribofuranoside), and AP site (apurinic/apyrimidinic site). AP site is tautomerized to give rise to two forms.

Shigenaga et al., 1989), 2) liquid chromatography/mass spectrometry or gas chromatography/mass spectrometry (Dizdaroglu et al., 2001; Weidner et al., 2011; Weimann et al., 2002), and 3) immunological assays using an anti-8-oxo-G antibody, including enzyme immunoassay, northern blotting, and immunoprecipitation (e.g. (Görg et al., 2008; Shan and Lin, 2006)). Therefore, most studies have assessed RNA oxidation based on 8-oxo-G production, while there have been no detailed investigations about the oxidation of $\mathrm{G}$ to 8 -oxo-G. Conversely, DNA oxidation studies suggest that the hydroxyl radical does not react with the guanine base by electron transfer but by direct addition of the radical onto the double bonds of guanine at the $\mathrm{C} 8$ and $\mathrm{C} 4$ positions. Subsequently, the former guanine adduct that is attacked at the $\mathrm{C} 8$ position reacts with oxygen to give rise to 8-oxo-G (Figure 2) (Candeias and
Steenken, 2000). In vivo study on iron metabolism revealed that 8 -oxo-G in human urine was correlated with the expression levels of ferritin, transferrin, and transferrin saturation in the plasma (Cejvanovic et al., 2018). Several reports showed a positive correlation between RNA oxidation and cellular iron levels (Honda et al., 2005; Zinskie et al., 2018). Using immunoprecipitation with anti-8-oxo-G antibodies, oxidized mRNA was isolated from AD brains. Microarray analyses of the oxidized mRNA showed that the oxidation levels were dependent on the mRNA species; for instance, $\mathrm{Cu}$ / Zn superoxide dismutase 1 or presenilin 1 was found to be highly oxidized compared to other genes (Shan et al., 2003; Shan and Lin, 2006). Subsequent studies consistently showed selective mRNA oxidation in ALS patients' brains, although which mRNAs were highly oxidized seemed to be different between 
ALS and AD (Shan et al., 2003; Chang et al., 2008). Selective oxidation of mRNA was also reported in ripened seed (Bazin et al., 2011), and other pathologies including ammonia toxicity (Görg et al., 2008) and formaldehyde exposure (Gonzalez-Rivera et al., 2020). Of note, highly oxidized mRNA species in their studies seemed to be inconsistent, suggesting that further study is necessary to clarify determinants to regulate selective mRNA oxidation.

\section{Abasic Site}

Abasic site is a sugar moiety formed after a nucleobase is cleaved off. It is estimated that the abasic sites in genomic DNA are the most abundantly generated oxidative modification. It yielded approximately 10,000 to 50,000 sites mediated by site-specific spontaneous reaction (Fresco and Amosova, 2017), enzymatic reaction (Dizdaroglu et al., 2017), and oxidative reaction (Greenberg, 2016) in a given day (Lindahl, 1993). In addition to the typical abasic site, which is termed the AP site, several different structures of abasic sites are generated by DNA oxidation, for instance 2-deoxypentos-4-ulose and 2deoxyribonolactone (Greenberg, 2016). While these atypical abasic sites have not been identified individually in oxidized RNA, our previous study using an aldehyde-reactive probe (ARP) revealed that AP site is generated by different types of oxidative reactions, including the iron mediated Fenton reaction, $\gamma$-irradiation, and peroxynitrite in vitro, and in cell cultures after oxidative stress with $\mathrm{H}_{2} \mathrm{O}_{2}$ (Tanaka et al., 2011). As shown in Figure 2, there are two tautomers, one that closed ring form and another that gives an open ring form which gives rise to an aldehyde group. These results indicate that an AP site is a biomarker for RNA oxidation. Conversely, Leumann's group have established a method for synthesizing RNA with an AP site at a specific location (Küpfer and Leumann, 2007a) and characterized their chemical property. Their studies revealed that the AP site in RNA was chemically more stable relative to that in DNA (Küpfer and Leumann, 2007b) and preferentially base-paired with $\mathrm{dA}$ or $\mathrm{dC}$ during reverse transcription (Küpfer et al., 2007). In order to measure the oxidation levels of individual RNA species including mRNA, our group isolated and quantified abasic RNA from total RNA by pull-down assay using ARP (Tanaka et al., 2011). While the mitochondrial mRNAs which are encoded in the mitochondrial genome had comparable oxidation levels to those of cytoplasmic mRNA under normal conditions, the mitochondrial mRNAs were oxidized distinctly higher than cytoplasmic mRNAs after $\mathrm{H}_{2} \mathrm{O}_{2}$ treatment. Consistent with the findings of selective mRNA oxidation monitored with 8-oxo-G (Shan and Lin, 2006; Görg et al., 2008; Bazin et al., 2011; Gonzalez-Rivera et al., 2020), the oxidation levels of mRNA based on the AP site quantity vary depending on mRNA studied. For instance, AP site levels of Oma1 mRNA were found to be about five-fold higher than that of ribosomal protein Rpl5 mRNA (unpublished data).

\section{Other Oxidative Derivatives}

The 8-oxo-A is known to be an intermediate of adenosine oxidation by xanthine oxidase (Wyngaarden and Dunn, 1957), however, it was also identified by mass spectrometry in polyA after oxidative reactions (Figure 2) (Alexander et al., 1987). 8oxo-A has been assumed to be a minor oxidized ribonucleoside relative to 8-oxo-G, since 8-oxo-dA was reported to be generated approximately one-tenth of 8-oxo-dG in DNA (Frelon et al., 2000; Choi et al., 2017). However, it was reported that 8-oxo-A adduct was increased in the most affected brain regions of late stage $\mathrm{AD}$ compared to the age-matched control subjects while 8-oxo-G adduct was decreased (Weidner et al., 2011). In vitro oxidoreduction of yeast RNA in the presence of NADH and $\mathrm{K}_{3} \mathrm{Fe}(\mathrm{CN})_{6}$ gave rise to the hydroxylated pyrimidines $5-\mathrm{OH}-\mathrm{C}$ and $5-\mathrm{OH}-\mathrm{U}$ in addition to 8-oxo-G and 8-oxo-A (Yanagawa et al., 1990; Yanagawa et al., 1992). Due to having lower redox potentials, those oxidized ribonucleosides would be susceptible to further oxidative modifications; for example, 5 -guanidinohydantoin was identified after a metal ion catalyzed oxidation of 8-oxo-G (White et al., 2005). In a separate study, Crean et al. reported the generation of spiroiminodihydantoin from 8 -oxo-G by a carbonate radical anion, using $2^{\prime}, 3^{\prime}, 5^{\prime}$-tri-O-acetyl-8-oxo-G instead of 8-oxo-G (Crean et al., 2005). Oxidation mediated by manganese porphyrin generated spiroiminodihydantoin and 5dehydroguanidinohydantoin as well (Tomaszewska-Antczak et al., 2015). Likewise, it was reported that oxidation of 8-oxoA generated the quinoidal intermediate that tends to form adducts with a variety of nucleophilic compounds (Nilov et al., 2013).

Transfer RNA contains a variety of modified nucleotides, some of which serve as targets for oxidative modifications. The oxidative desulfration of thiouridine which contains sulfur in place of carbonyl oxygen atom has been investigated in detail. Nawrot's group reported that the 2-thiouridine (S2U) is oxidized via a sequence of intermediates starting with sulefenic acid $(-\mathrm{SOH})$, and then becoming sulfinic acid $\left(-\mathrm{SO}_{2} \mathrm{H}\right)$, and then sulfonic acid $\left(-\mathrm{SO}_{3} \mathrm{H}\right)$, which is desulfrated to generate 4pyrimidinone ribofuranoside (H2U) (Figure 2) and uridine by $\mathrm{H}_{2} \mathrm{O}_{2}$ treatment (Sochacka et al., 2011) under physiological pH conditions (Sochacka et al., 2013) and cytochrome $c$ (cyt c) mediated peroxidation (Sierant et al., 2018). Conversely, selenouridine which contains selenium instead of sulfur is oxidized in a similar pathway; however Payne et al. investigated redox chemistry between 2 -selenouridine and 2thiouridine to find that oxidized selenouridine was more prone to be reduced in the presence of antioxidants such as glutathione and ascorbate than oxidized thiouracil since selenouridine was highly resistant to oxidative deprivation of selenium which is the key atom to catalyze redox reaction (Payne et al., 2017).

\section{Cross-Linking}

There have been numerous studies regarding RNA-protein artificial cross-linking, mainly for mapping between RNA and its associated RNA binding proteins by means of site-specific probe insertion and UV irradiation (i.e. (Van Nostrand et al., 2016; Lin and Miles, 2019; Sharma et al., 2021)). For pathophysiological cross-linking, Mirzaei and Regnier reported 
RNA and protein cross-linking in yeast after $\mathrm{H}_{2} \mathrm{O}_{2}$ treatment (Mirzaei and Regnier, 2006). Proteomic mass spectrometric analysis for the isolated carbonylated proteins showed that the cross-linking was mainly between rRNA and ribosomal proteins at multiple sites. Cross-links were formed mainly between lysine, arginine, methionine, and tyrosine residues in ribosomal proteins, and guanine residue in rRNA. To this end, we have shown the in vitro oxidative cross-linking between tRNA and cyt $c$ (Tanaka et al., 2012). Cyt $c$ catalyzes the peroxidation of mitochondrial membrane lipids in the presence of $\mathrm{H}_{2} \mathrm{O}_{2}$ (Bayir et al., 2006; Yin et al., 2017) and exhibiting binding affinity between RNA and the heme $c$ moiety. In this case, $\mathrm{G}$ appeared preferentially subject to oxidative modifications, including depurination and cross-linking, while the cross-linked structure between ribonucleotide and amino acid has not been identified (Tanaka et al., 2012). Thus, although there have been few studies in this field until now, it would be possible that oxidative stress induces RNA-protein cross-linking, which may contribute to impaired translation, deregulation of RNA binding proteins, or deteriorated protein homeostasis due to protein aggregation.

\section{Strand Scission}

Strand scission would be one of the major outcomes observed due to RNA oxidative modification. Approximately $40 \%$ of in vitro reactions between hydroxyl radicals and RNA strands lead to strand scission, in which nucleobase radicals are primarily generated, followed by $\mathrm{H}$-abstraction from ribose rings, and resulting in a strand break (Lemaire et al., 1984; Jones and O'Neill, 1990). Joyner et al. investigated the mechanism of oxidative RNA cleavage and formation of $3^{\prime}$ and $5^{\prime}$-overhangs using MALDI-TOF MS (Joyner et al., 2013). HIV-1 Rev Response Element was fragmented at various sizes by oxidation in the presence of ascorbate, $\mathrm{H}_{2} \mathrm{O}_{2}$, and $\mathrm{Fe}(\mathrm{II})$ EDTA. The cleavage site and chemical structure of the terminal overhangs were identified by their molecular weights. In addition to $3^{\prime}-\mathrm{PO}_{4}, 2^{\prime}, 3^{\prime}$-cyclic $\mathrm{PO}_{4}$ and $3^{\prime}$-phoshoglycolate were the main $3^{\prime}$-end structures, while $5^{\prime}-\mathrm{PO}_{4}$ and $5^{\prime}-\mathrm{OH}$ were the main $5^{\prime}$-end structures. Based on previous DNA studies, it was deduced that there are three different modes of cleavage reactions, hydrolysis, $\mathrm{H}$-abstraction, and $2^{\prime}-\mathrm{OH}$ mediated transesterification: $3^{\prime}-\mathrm{PO}_{4}$ was generated by the hydrolytic process; $3^{\prime}$-phosphoglycolate formation occurred by oxidative $4^{\prime}-\mathrm{H}$ abstraction in the ribose moiety, and base 2-propenal was generated as a byproduct. In addition, $2^{\prime}, 3^{\prime}$ cyclicPO $\mathrm{PO}_{4}$ could be generated due to $2^{\prime}-\mathrm{OH}$ mediated transesterification (Joyner et al., 2013). Ingle et al. investigated oxidative cleavage in the GUA base triple in rat sarsin/ricin loop RNA. The reactivity of the GUA triplet with sodium borohydride, and the products analyses showed that the aldehyde moiety was generated at the $5^{\prime}$-end possibly due to $5^{\prime}$ hydrogen abstraction (Ingle et al., 2014). To date, several nucleases are known to cleave DNA $3^{\prime}$-phosphoglycorate (Kuo et al., 1993; Inamdar et al., 2002; Povirk et al., 2007), however no ribonuclease to cleave RNA 3 '-phosphoglycorate has been reported. It may be important to investigate this enzyme activity for understanding RNA homeostasis during oxidative stress.

\section{EFFECTS OF RNA OXIDATION ON TRANSLATION}

To our knowledge, since inhibition of the aminoacylation activity by RNA oxidation was first reported in 1959 (Preiss et al., 1959), translational activity has been investigated to assess biological consequences of RNA oxidation. Here we review translational alternation by oxidation of mRNA and rRNA mainly modified with 8-oxo-G or abasic site. As for tRNA, we review here the effects of oxidative desulfration of thiouridine.

\section{tRNA Oxidation}

In vitro aminoacylation of tRNA after oxidation were substantially reduced for glutamic acid, glutamine and lysine compared to other amino acids. Their tRNAs contain thiouridine residues, which were desulfurated (Rao and Cherayil, 1974). It was also reported that desulfrated tRNAs substantially reduced ribosome binding depending on the mRNA template (Walker and RajBhandary, 1972). Since thiolated uridines are frequently located at the wobble position, the first nucleotide of anticodon, it is of interest how codon-anticodon interaction is changed by thiouridine desulfration. To this end, Sochacka et al. investigated base pairing with $\mathrm{S} 2 \mathrm{U}$ and $\mathrm{H} 2 \mathrm{U}$ which were incorporated into RNA duplex oligonucleotides with A or G as the complementary nucleotides. Based on thermodynamic analyses and the computational calculation, it was found that the H2U-G paired duplex was thermodynamically more stable than the H2U-A paired duplex, possibly because there are two putative hydrogen bonds between $\mathrm{H} 2 \mathrm{U}$ and $\mathrm{G}$, whereas there is only one hydrogen bond between $\mathrm{H} 2 \mathrm{U}$ and A. Thus, although S2U is known to form a base pair with A, H2U seems to base pair with G, which may alter decoding kinetics by oxidation of thiouridine at the wobble position (Sochacka et al., 2015).

\section{mRNA Oxidation}

Previously we reported on translational inhibition of oxidized mRNA in vitro (Tanaka et al., 2007). Using cell free translation systems, oxidized luciferase mRNA was found to compromise translational activity, even if the mRNA was incubated with only iron under aerobic conditions, and in the absence of ascorbate and $\mathrm{H}_{2} \mathrm{O}_{2}$. In addition, we observed the accumulation of short polypeptides, possibly due to premature termination as they were mostly N-terminal fragments. These fragments were also generated in cell cultures transfected with the oxidized mRNA or treated with paraquat following transfection with non-oxidized mRNA. But the peptide fragments were observed only in the presence of a proteasome inhibitor, MG132. Together, these observations indicate that the abnormal polypeptides were readily eliminated by proteasomes. In addition, we found that the catalytic activity of the full-length luciferase generated using oxidized mRNA is compromised, suggesting that the protein structure so generated was altered (Tanaka et al., 2007). Consistent with the notion that protein synthesis using oxidized mRNA leads to the generation of abnormal proteins, overexpression using oxidized mRNA encoding EGFP in HEK293 cells has been shown to generate an EGFP protein that aggregated in abnormal cytoplasmic foci. This observation 
indicates that EGFP generated with oxidized mRNA tended to be aggregation-prone, possibly due to structural changes caused by miscoding (Shan et al., 2003). Together, these studies demonstrated that oxidized mRNA expression in cells would lead to abnormal polypeptide production, although it is not known exactly how it occurred.

Recent studies have expanded mechanistic understanding of the above observations using mRNA templates which incorporated 8-oxo-G, AP site, or other oxidative nucleotides at a specific position (Simms et al., 2014; Calabretta et al., 2015; Hoernes et al., 2018a; Hoernes et al., 2018b; Thomas et al., 2019). Zaher's group revealed, when an mRNA oligomer was incubated with wheat germ or an $E$. coli derived in vitro translation system, the translation process would stop or take an extremely long pause at the 8-oxo-G site wherever it was located within a triplet codon (Simms et al., 2014). This in vitro study demonstrated that 8-oxo-G in mRNA largely inhibits translation elongation. Later it was found that inhibition of translation elongation is a common dysfunctional mechanism for other oxidized derivatives. Calabretta et al. investigated amino acid incorporation at the lesioned site, where 8-oxo-G, 8-oxo-A, 5-OH-C, or 5-OH-U was incorporated into a synthetic mRNA oligomer using rabbit reticulocyte lysate. They found the translated products were substantially truncated at the lesioned site where 8-oxo-G, 8oxo-A, 5-OH-C, or 5-OH-U was inserted, while 1,N6ethenoAdo, 3,N4-ethenoC, or abasic site showed no translation elongation at the insertion site (Calabretta et al., 2015). Thus, all the oxidized ribonucleosides tested appear to cause translation arrest. In this situation, the No-Go decay system is activated and endoribonucleolytic degradation of the mRNA stalled on the ribosome triggers downstream quality control pathways (Simms et al., 2017). Yeast mutants dom $34 \Delta$ and $\operatorname{xrn} 1 \Delta$, which correspond to the ribonucleolytic activity, showed an increase of the 8-oxo-G levels in polyA RNA. This observation indicates that once ribosomes are stalled at the oxidative modified sites of mRNA, a No-Go decay enzyme complex is recruited to the sites and starts to degrade of the mRNA (Simms et al., 2017; Yan et al., 2019) interacting with Rps3/uS3 at the entry tunnel of the ribosomal small subunit (Simms et al., 2018).

In terms of miscoding, base-pairing against 8-oxo-G on the ribosome has been investigated using an in vitro system (Thomas et al., 2019). 8-oxo-G at the first codon preferentially base paired with $\mathrm{C}$ while 8-oxo-G at the second codon tended to base pair with A taking presumably syn conformation. Under translation error prone conditions, such as treatments with paromomycin, streptomycin or having an error-prone ribosome mutant, increased the rate of peptide bond formation in both basepairings. Thus, these findings provide evidence that 8 -oxo-G in mRNA has potential to cause amino acid misincorporation during the coding process, despite the fact that the peptide bond formation rate was very low (Thomas et al., 2019). Erlacher's group investigated translation products from mRNA containing non-standard codon nucleotides including AP site using mass spectrometry to identify decoding amino acid (Hoernes et al., 2018a). When one AP site was inserted in the third codon (A-U$\mathrm{AP}$ site) in a synthesized reporter mRNA, the in vitro bacterial translation system translated the codon into predominantly as Ile (95\%), but also a small amount of Met (5\%). Even though the translation was not efficient, the AP site was found to be decoded in certain nucleotides but not a single nucleotide. Conversely, HEK293T eukaryotic cells did not translate the modified codon (Hoernes et al., 2018a). In addition, they investigated the translational termination at stop codons with several modified ribonucleotides including AP site as well (Hoernes et al., 2018b). Triple AP sites completely inhibited the peptide release in both bacterial and eukaryotic release factors. Insertion of an abasic site at the second or third codon inhibited peptide release; the exact influence was significantly different based on the release factor and the abasic position (Hoernes et al., 2018b).

\section{rRNA Oxidation}

Honda et al. investigated translational activity of in vitro oxidized ribosomes. As expected, iron catalyzed oxidation significantly reduced the translational activity, which was measured by radiolabeling amino acid incorporated in the proteinaceous fraction (Honda et al., 2005). The peptidyl transferase center (PTC) region in the ribosome plays a pivotal role in aminoacyltransferase activity, where it is mediated by highly structured rRNA but not associated ribosomal proteins. Polacek's group chemically synthesized in E. coli large rRNA in which certain ribonucleotide was replaced with an abasic site in the PTC region and integrated to reconstitute a whole ribosome. It was found that translational activity, including peptide bond formation, was reduced by substitution at A2450, A2451, or C2063, whereas substitution in positions, U2585 and U2506, increased translational activity (Erlacher et al., 2005; Erlacher et al., 2006; Amort et al., 2007; Chirkova et al., 2010). Schrode et al. investigated translational activity of $16 \mathrm{~S}$ rRNA modified by replacing the AP sites at A1492 and A1493, which are critical for A-site binding of aminoacyl tRNA, and this was found to abolish translational activity (Schrode et al., 2017). Willi et al. extended the investigation using hydroxylated ribonucleotides (Willi et al., 2018). Large 23S rRNA which was individually substituted to 8oxo-G (G2447), 8-oxo-A (A2451 or A2602), 5-OH-C (C2063) or $5-\mathrm{OH}-\mathrm{U}$ (U2585 or U2506) in the PTC region was synthesized and reconstituted the ribosome. It turned out that 8-oxo-A2451 caused slow peptide bond formation and 5-OH-U2585 interfered with A-site tRNA accommodation, while 5-OH-U2506, 8-oxoA2602, and 8-oxo-G2447 did not affect the translational activity. Conversely, 5-OH-C2063 facilitated translation (Willi et al., 2018). Thus, these results suggested that depurinated or oxidative modifications in rRNA do not necessarily impair ribosomal translational activity, but rather the effect is dependent on the modified position.

\section{OXIDATIVELY MODIFIED RNAS AS POTENTIAL SIGNALING MODULATORS Oxidized Ribonucleoside as Redox Catalyst and Antioxidant}

Yanagawa et al. reported that hydroxylated ribonucleosides, 5$\mathrm{OH}-\mathrm{C}, 5-\mathrm{OH}-\mathrm{U}$, and 8-oxo-G, are capable of facilitating the 
oxidoreduction between $\mathrm{K}_{3} \mathrm{Fe}(\mathrm{CN})_{6}$ and $\mathrm{NADH}$. The redox potentials (E7) for 5-OH-C, 5-OH-U, 8-oxo-A and 8-oxo-G were found to be $0.42,0.44,0.72$, and $0.38 \mathrm{~V}$, respectively. Considering the redox potentials of $\mathrm{K}_{3} \mathrm{Fe}(\mathrm{CN})_{6}(0.42 \mathrm{~V})$ and $\mathrm{NADH}(-0.35 \mathrm{~V})$, it is reasonable that $5-\mathrm{OH}-\mathrm{C}, 5-\mathrm{OH}-\mathrm{U}$, and 8-oxo-G but not 8-oxo-A could catalyze the oxidoreduction between the two compounds (Yanagawa et al., 1992). It is possible that those oxidized ribonucleosides are more reactive in the tested conditions than the standard ribonucleosides since the redox potentials (E7) of A and G were 1.42 and $1.29 \mathrm{~V}$, respectively (Steenkcn and Jovanovic, 1997).

As mentioned above, due to the low redox potential, 8-oxo-G is readily oxidized by the reaction with ROS (Crean et al., 2005; White et al., 2005), suggesting that this oxidized ribonucleoside could function as an ROS absorber. Lee et al. reported that levels of hydroxyl radical generated by Fenton reaction, peroxynitrite, and superoxide anion could be reduced by co-incubation with 8 oxo-G or 8-oxo-dG, equivalent or even more efficient than $\mathrm{N}$-acetyl cysteine (Lee et al., 2013). Thus, due to its relatively low redox potential, oxidized ribonucleoside such as 8-oxo-G could function as a catalyst for the oxidoreduction within a certain range of redox potentials or as an antioxidant to remove the ROS in cells as well as in biofluid.

\section{Free 8-Oxo-GTP as a Signaling Modulator}

Although 8-oxo-GTP is hydrolyzed to 8-oxo-GMP by MutT/ MTH1 (Taddei et al., 1997), the cytoplasmic 8-oxo-GTP pool increased during oxidative stress (i.e. approx. 4 and $9 \mathrm{pmol} / \mathrm{mg}$ protein in control and stress conditions in PC12 cells, respectively (Bolin and Cardozo-Pelaez, 2009)). Chung's group investigated the effects of free 8-oxo-GTP on several small G-proteins: in HEK293 cell lysate the recombinant Ras was activated and enhanced the downstream Ras-ERK signaling pathway by 8 oxo-GTP $\gamma$ S more efficiently than GTP $\gamma$ S, the unhydrolyzable analog of GTP. In contrast, recombinant Racl and Cdc42 were activated by GTP $\gamma$ S, while they were inactivated by 8-oxo-GTP $\gamma$ S (Yoon et al., 2005). Additionally, the production of NADPH oxidase-derived superoxide anion was elevated by GTP $\gamma$ S, while it was decreased by 8 -oxo-GTP $\gamma \mathrm{S}$ in human neutrophil lysate activated by phorbol myristate acetate (PMA). Consistently, activity of Racl which is bound to the active form of $\mathrm{NADH}$ oxidase was increased by GTP $\gamma \mathrm{S}$ but decreased by 8-oxo-GTP $\gamma \mathrm{S}$, suggesting that 8 -oxo-GTP is a negative modulator to inflammatory responses involving the NADPH oxidase and Racl complex (Kim et al., 2007).

In the presence of nitric oxide, the soluble guanylyl cyclase (sGC) is activated to catalyze GTP to cyclic-GMP (cGMP), the second messenger for various downstream signaling for proliferation, synaptic plasticity, vasodilation, and platelet aggregation. Bolin and Cardozo-Pelaez investigated the effect of 8-oxo-GTP on sGC (Bolin and Cardozo-Pelaez, 2009). They observed that when purified sGC was incubated in the presence of a NO donor with different doses of 8-oxo-GTP, cGMP production was decreased in a manner of reducing Vmax without altering the value of $\mathrm{Km}$. Conversely, sGC activity was decreased in cultured cells after a copper/ascorbate mediated Fenton reaction, a condition which did not induce the reduction of the intracellular GTP pool or oxidative damage of the protein. Instead, it would be, in part, due to the increase in intracellular 8oxo-GTP (Bolin and Cardozo-Pelaez, 2009).

\section{Oxidized Mitochondrial RNA as an Inflammation Modulator}

Oxidized mitochondrial DNA transfected into the cytoplasm or injected into animal tissue, induced an inflammatory response mediated by the NLRP3 inflammasome (Collins et al., 2004; Shimada et al., 2012). Saxena et al. investigated the immune response by oxidized mitochondrial RNA (mtRNA) in a mouse bone marrow derived macrophage (Saxena et al., 2017). When oxidized mtRNA isolated from $\mathrm{H}_{2} \mathrm{O}_{2}$ treated $\mathrm{HAl}$ hamster fibroblast cells was transfected, production of proinflammatory cytokines, IL-6, MCP-1, and type I interferon were found lower than those of control mtRNA isolated from untreated cells. In contrast, when oxidized mtRNA derived from $\mathrm{H}_{2} \mathrm{O}_{2}$ treated THP-1, human monocyte cells were transfected to the differentiated THP-1 induced by PMA, the inflammatory response to induce IL- 6 and TNF- $\alpha$ was more activated relative to that of control mtRNA (Ilic et al., 2019). Taken together, it seems to be inconclusive whether oxidized mtRNA in cytoplasm shows differential effects on inflammatory response compared to control mtRNA. However, it is possible that oxidation of mtRNA may acquire differential inflammatory responses under certain conditions.

\section{Oxidized RNA in Apoptotic Pathways}

Wang et al. investigated genome-wide analysis to identify selectively oxidized miRNAs under oxidative stress conditions in a rat heart cell line. They revealed that miR-184 was one of the highly oxidized miRNAs. The oxidized miR-184, but not nonoxidized miR-184, preferentially interacted with two antiapoptotic genes, Bcl-xl and Bcl-w mRNA at $3^{\prime}$-UTR and lead to their downregulation (Wang et al., 2015). Although the oxidized positions in the miRNA have not been identified, the putative mismatch between oxidized miRNA184 and the target $3^{\prime}$-UTR indicated that several G residues in miRNA184 were base-paired with $\mathrm{A}$, the nucleoside that base paired with 8-oxo-G (Koga et al., 2013). It should be pointed out that those putative oxidized $G$ sites are mostly located in the $G$ repeat sequence, which is more susceptible to oxidation compared to a single $G$ due to lower redox potential (Burrows and Muller, 1998; Margolin et al., 2008). Degradation of anti-apoptotic genes due to binding the oxidized miRNA would induce an acceleration of cellular apoptosis. This observation suggests a molecular mechanism by which oxidative stress induces cellular apoptosis. Moreover, this would be the case in vivo because injection of oxidized miR-184 into the heart of an ischemia/reperfusion animal model potentiated the reduction of $\mathrm{Bcl}-\mathrm{xl}$ and $\mathrm{Bcl}-\mathrm{w}$, while increasing the apoptotic cells and infarct size compared to control miR-184 injection (Wang et al., 2015). Thus, miRNA184 acquires the novel function of binding to new target mRNAs by oxidative modification which in turn regulates apoptotic signaling.

Sekiguchi's group has identified several proteins that can bind to oxidized RNA from bacteria and mammalian cells by screening 
RNA oligonucleotides containing 8-oxo-G as a probe; polynucleotide phosphorylase 1 (PNPase) (Hayakawa et al., 2001), Y box-binding protein (YB-1) (Hayakawa et al., 2002), heterogeneous nuclear ribonucleoprotein splice form D0 (HNRNPD or AUF1) and C1 (HNRPNC) (Hayakawa et al., 2010; Ishii et al., 2015), and poly(C) binding protein (PCBP) 1 (Ishii et al., 2018) and PCBP2 (Ishii et al., 2020). In vitro binding tests showed that PCBP1 and PCBP2 bind to a highly enriched 8oxo-G oligo RNA in comparison to AUF1, which efficiently binds to a single 8-oxo-G containing oligo RNA. PCBP1 deficient HeLa cells showed lower capase-3 activation and poly (ADP-ribose) polymerase 1 (PARP1) cleavage after $\mathrm{H}_{2} \mathrm{O}_{2}$ treatment leading to a higher survival rate. In addition, PCBP1 mutant in KH1 domain showed deficiency both in 8-oxo-G binding and PARP-1 cleavage (Ishii et al., 2018). In contrast, PCBP2 deficient HeLa cells exhibited growth retardation, with increasing caspase-3 activity, cleaved PARP, and apoptosis under oxidative stress (Ishii et al., 2020). Together, these results indicate that PCBP1 and PCBP2 modulates apoptotic signaling in an opposite direction after binding to highly oxidized RNA. While there are many factors known to be involved in regulating cellular apoptosis, the PCBP1 and PCBP2 may involve in mediating the apoptosis in response to cellular RNA oxidation.

It is well established that cyt $c$ catalyzes peroxidation through the heme iron. To this end, we have reported that cyt $c$ readily oxidized tRNA to form a cross-link in the presence of $\mathrm{H}_{2} \mathrm{O}_{2}$ (Tanaka et al., 2012), partly due to cyt $c$ binding to tRNA via heme $c$ domain (Gorla and Sepuri, 2014). Under these conditions, the cyt $c$-tRNA complex would be released from a lipid vesicle composed of cardiolipin, the main mitochondrial membrane component. As a result, the oxidative cross-linking of cyt $c$ with tRNA could facilitate the release of cyt $c$ from mitochondria, and activate cellular apoptosis (Tanaka et al., 2012). Nevertheless, it should be pointed out that Mei et al. had reported that the cyt $c$-tRNA non-covalent complex could bind to Apaf1 (Mei et al., 2010) and inhibit caspase activation.

\section{miRNA Processing Regulated by Its Oxidation}

Apurinic/apyrimidinic endonuclease1 (APE1) is long known as the endodeoxyribonuclease which cleaves off DNA strand specifically at the $5^{\prime}$ side to the AP site during the process of DNA base excision repair. Later, this enzyme was found to be able to cleave c-myc mRNA (Barnes et al., 2009) and was confirmed to be an endoribonuclease that cleaves at the RNA abasic site (Berquist et al., 2008). Moreover, Tell's group reported that APE1-knockdown cells contain an increased level of oxidized RNA, indicating that APE1 plays a critical role in clearance of oxidized RNAs (Vascotto et al., 2009). Recently, they identified the interacting miRNAs which are corelated to the cancer development and characterized their maturation processes (Antoniali et al., 2017). Among them, miR-221 and miR-222 which are involved in the expression of PTEN, the tumor suppressor gene, was upregulated in cells treated with $\mathrm{H}_{2} \mathrm{O}_{2}$. Their further analysis revealed that the precursors, pri-miR221 and pri-miR222 were elevated while their mature forms were decreased, either by APE1 knockdown, APE1 mutant overexpression, or the endoribonuclease inhibitor. Together, their findings suggest that APE1 regulates the miRNA processing, possibly through AP endoribonuclease activity. As a matter of fact, APE1 knockdown cells increased the oxidative AP site levels of miR221, while the revertant cells due to APE1 overexpression returned to control levels. Certainly, APE1 knockdown cells upregulated PTEN expression, and the expression levels of APE1 were positively correlated with those of miR221 but reciprocally correlated with those of PTEN in human tumor tissue (Antoniali et al., 2017). These results indicated that the miRNA processing and maturation are regulated through AP site formation in the miRNAs and their degradation by APE1.

\section{EFFECTS OF ENZYMATICALLY CREATED RNA AP SITE}

\section{AP Sites for Antiviral Defense}

AP site formation by depurination is not only due to RNA oxidative modification by ROS, but is also known to be created by proteins. Here we discuss mimic oxidative modification and its biological consequences. Endo and Tsurugi discovered that ricin A-chain depurinated 28S rRNA at a conserved A4324 in the sarcin/ricin loop (Endo et al., 1987; Endo and Tsurugi, 1987), which has an essential role on translocation step associated with elongation factor binding (Montanaro et al., 1975; Shi et al., 2012). To date, several proteins and families with the RNA $\mathrm{N}$-glycosidase activity have been identified mainly in plants, fungi, and bacteria. These ribosome inactivating proteins (RIPs) caused complete inactivation of ribosomal function leading to cell death, although it is arguable whether the potent cytotoxicity of RIPs is only due to the $\mathrm{N}$-glycosidase activity (Hudak et al., 2004). Pokeweed antiviral protein (PAP) was first characterized as an antiviral protein because plant virus infection was inhibited by coinoculation (Wyatt and Shepherd, 1969; Tomlinson et al., 1974). PAP depurinates A residues not only in the host rRNA but also in several viral RNAs following recognizing the cap structure of the RNAs (Hudak et al., 2000; Hudak et al., 2002). As mentioned in the previous section, depurinated viral RNA such as Bromo mosaic virus RNA3 was not translated properly and rapidly degraded by No-Go decay system (Gandhi et al., 2008). Although the molecular mechanism to recognize viral RNA has not been fully understood yet, depurination of both rRNA and viral mRNA in the infected cells seems a quite potent modification to cause malfunction on viral protein synthesis. Organisms may have evolved to cope with viral infection by taking advantage of the same chemical modification as occurred in oxidative stress to the pathogen RNA and eliminating it using the No-Go decay RNA quality control system.

\section{AP Sites to Regulate R-Loop}

$\mathrm{R}$-loop is a three-stranded nucleic acid structure. It consists of a DNA-RNA hybrid and displaced single-stranded of DNA. It is formed during transcription when the nascent RNA reanneals 
with the template DNA strand. R-loops play vital roles in regulating gene expression, DNA replication, and DNA and histone modifications. It is thought to regulate several cellular processes including immunoglobulin class switch recombination, transcriptional gene expression, mitochondrial DNA replication, and epigenetic modification. Conversely, dysregulated R-loop formation causes DNA damage and genome instability, and lead to a number of human diseases, including neurological disorders, cancer, and autoimmune diseases (see review (García-Muse et al., 2019; Hegazy et al., 2020)). However, it is not well understood how R-loop structure is stabilized or resolved. Recently proteomic analysis for the binding factors on R-loop revealed hundreds of proteins involved in RNA binding, splicing, helicase, transcription termination, and telomere regulation (Wang et al., 2018). Among them, the DNA damage excision repair enzymes, APE1, and methylpurine DNA glycosylase (MPG) were further investigated (Liu et al., 2020). It was found that RNA substrates of APE1 and MPG co-localized to the R-loop regions based on genome-wide analysis. The MPG knockdown cells temporally decreased abasic RNA as well as R-loop regions. Purified MPG had a $N$-glycosylase activity on the RNA strand in the RNA-DNA duplex in vitro. In addition, APE1 incises the abasic RNA strand in the RNA-DNA duplex (Liu et al., 2020). These findings suggested that the RNA strand in the R-loop is depurinated by MPG and cleaved off at the AP site by APE1. It is possible that these two enzymes collaboratively regulate the R-loop stability via the abasic site formation and the ribonucleolytic cleavage of the abasic RNA strand.

The scheme in Figure $\mathbf{1}$ depicts the summary of potential pathological and physiological effects of oxidized nucleoside, and/ or RNA. While these oxidative modifications not only could lead to impairing their normal physiological functions, they could also modulate cellular signaling pathways, such as inducing cellular apoptosis in response to oxidative stress.

\section{PERSPECTIVES}

The level of oxidized cellular RNA is higher than that of genomic DNA under oxidative stress conditions, in vitro and in vivo, observed with $\mathrm{H}_{2} \mathrm{O}_{2}$ treatment (Hofer et al., 2005), UV irradiation (Wamer and Wei, 1997), or treatment with hepatocarcinogen 2nitropropane (Fiala et al., 1989). These effects, in part, are due to

\section{REFERENCES}

Alenko, A., Fleming, A. M., and Burrows, C. J. (2017). Reverse Transcription Past Products of Guanine Oxidation in RNA Leads to Insertion of A and C Opposite 8-Oxo-7,8-Dihydroguanine and A and G Opposite 5-Guanidinohydantoin and Spiroiminodihydantoin Diastereomers. Biochemistry 56, 5053-5064. doi:10. 1021/acs.biochem.7b00730

Alexander, A. J., Kebarle, P., Fuciarelli, A. F., and Raleigh, J. A. (1987). Characterization of Radiation-Induced Damage to Polyadenylic Acid Using High-Performance Liquid Chromatography/tandem Mass Spectrometry. Anal. Chem. 59, 2484-2491. doi:10.1021/ac00147a010 the DNA protection exerted by nucleosomal histone proteins against iron-mediated damage (Enright et al., 1992) and the presence of robust DNA oxidation damage repair/degradation systems (Chapman et al., 2012; Chatterjee and Walker, 2017). On the other hand, substantial evidence shows the presence of enzyme systems that eliminate RNA oxidation; APE1 is an endonuclease that breaks down the abasic RNA (Vascotto et al., 2009). PNPase has been identified as a 8-oxo-G binding protein (Hayakawa et al., 2001), and later it was suggested to be involved in degradation of oxidized RNA (Wu and Li, 2008). MutT/MTH1 is a pyrophophatase that catalyzes the hydrolysis of 8-oxo-GTP to 8-oxo-GMP to exclude incorporation of the oxidized ribonucleotide into RNA (Taddei et al., 1997). Moreover, the No-Go decay system, which degrades many different types of abnormal mRNA, once they are stalled on the ribosome, plays a pivotal role on the elimination of oxidized mRNA (Gandhi et al., 2008; Yan and Zaher, 2019). Therefore, it is unlikely that high RNA oxidation levels are due to the absence of oxidized RNA removing systems. Instead, it may be possible that biosystems have evolved to be tolerant of RNA oxidation relative to DNA oxidation. Oxidized RNAs may not be eliminated instantly in cells. Recent studies have revealed emerging roles for oxidized RNA as signaling modulators in response to cellular oxidative stress. The level of oxidized RNAs might be elaborately controlled to prevent a global protein homeostasis crisis, as well as to accommodate the regulatory functions of oxidized RNA. Thus, it is clear that further research on oxidized RNA is essential.

\section{AUTHOR CONTRIBUTIONS}

MT contributed to planning the entire framework and concept. Also MT prepared the draft and a figure. PB critically edited the article. All authors contributed to the article and approved the submitted version.

\section{FUNDING}

This research was supported by the Intramural Research Program of the National Institutes of Health; National Heart, Lung, and Blood Institute, and NIH Grants AG11370 and NS056218.

Amort, M., Wotzel, B., Bakowska-Zywicka, K., Erlacher, M. D., Micura, R., and Polacek, N. (2007). An Intact Ribose Moiety at A2602 of 23S rRNA Is Key to Trigger Peptidyl-tRNA Hydrolysis during Translation Termination. Nucleic Acids Res. 35, 5130-5140. doi:10.1093/nar/ gkm539

Antoniali, G., Serra, F., Lirussi, L., Tanaka, M., D’Ambrosio, C., Zhang, S., et al. (2017). Mammalian APE1 Controls miRNA Processing and its Interactome Is Linked to Cancer RNA Metabolism. Nat. Commun. 8, 797. doi:10.1038/s41467017-00842-8

Athavale, S. S., Petrov, A. S., Hsiao, C., Watkins, D., Prickett, C. D., Gossett, J. J., et al. (2012). RNA Folding and Catalysis Mediated by Iron (II). PLoS One 7, e38024. doi:10.1371/journal.pone.0038024 
Barnes, T., Kim, W.-C., Mantha, A. K., Kim, S.-E., Izumi, T., Mitra, S., et al. (2009). Identification of Apurinic/apyrimidinic Endonuclease 1 (APE1) as the Endoribonuclease that Cleaves C-Myc mRNA. Nucleic Acids Res. 37, 3946-3958. doi:10.1093/nar/gkp275

Bayir, H., Fadeel, B., Palladino, M. J., Witasp, E., Kurnikov, I. V., Tyurina, Y. Y., et al. (2006). Apoptotic Interactions of Cytochrome C: Redox Flirting with Anionic Phospholipids within and outside of Mitochondria. Biochim. Biophys. Acta (BBA) - Bioenerg. 1757, 648-659. doi:10.1016/j.bbabio.2006.03.002

Bazin, J., Langlade, N., Vincourt, P., Arribat, S., Balzergue, S., El-Maarouf-Bouteau, H., et al. (2011). Targeted mRNA Oxidation Regulates Sunflower Seed Dormancy Alleviation during Dry After-Ripening. Plant Cell 23, 2196-2208. doi:10.1105/tpc.111.086694

Beckman, K. B., and Ames, B. N. (1998). The Free Radical Theory of Aging Matures. Physiol. Rev. 78, 547-581. doi:10.1152/physrev.1998.78.2.547

Berens, C., Streicher, B., Schroeder, R., and Hillen, W. (1998). Visualizing MetalIon-Binding Sites in Group I Introns by Iron(II)-mediated Fenton Reactions. Chem. Biol. 5, 163-175. doi:10.1016/s1074-5521(98)90061-8

Berquist, B. R., McNeill, D. R., and Wilson, D. M., 3rd (2008). Characterization of Abasic Endonuclease Activity of Human Ape1 on Alternative Substrates, as Well as Effects of ATP and Sequence Context on AP Site Incision. J. Mol. Biol. 379, 17-27. doi:10.1016/j.jmb.2008.03.053

Bochkov, V. N., Oskolkova, O. V., Birukov, K. G., Levonen, A.-L., Binder, C. J., and Stöckl, J. (2010). Generation and Biological Activities of Oxidized Phospholipids. Antioxid. Redox Signaling 12, 1009-1059. doi:10.1089/ars. 2009.2597

Bolin, C., and Cardozo-Pelaez, F. (2009). Characterization of Oxidized Guanosine $5^{\prime}$-triphosphate as a Viable Inhibitor of Soluble Guanylyl Cyclase. Free Radic. Biol. Med. 46, 828-835. doi:10.1016/j.freeradbiomed.2008.12.021

Boveris, A., and Cadenas, E. (1975). Mitochondrial Production of Superoxide Anions and its Relationship to the Antimycin Insensitive Respiration. FEBS Lett. 54, 311-314. doi:10.1016/0014-5793(75)80928-8

Boveris, A., and Chance, B. (1973). The Mitochondrial Generation of Hydrogen Peroxide. General Properties and Effect of Hyperbaric Oxygen. Biochem. J. 134, 707-716. doi:10.1042/bj1340707

Burrows, C. J., and Muller, J. G. (1998). Oxidative Nucleobase Modifications Leading to Strand Scission. Chem. Rev. 98, 1109-1152. doi:10.1021/cr960421s

Calabretta, A., Küpfer, P. A., and Leumann, C. J. (2015). The Effect of RNA Base Lesions on mRNA Translation. Nucleic Acids Res. 43, 4713-4720. doi:10.1093/ nar/gkv377

Candeias, L. P., and Steenken, S. (2000). Reaction of HO. With Guanine Derivatives in Aqueous Solution: Formation of Two Different Redox-Active OH-Adduct Radicals and Their Unimolecular Transformation Reactions. Properties of G(H). Chem. Eur. J. 6, 475-484. doi:10.1002/(sici)1521-3765(20000204)6:3<475:: aid-chem475>3.0.co;2-e

Cejvanovic, V., Kjær, L. K., Bergholdt, H. K. M., Torp-Pedersen, A., Henriksen, T., Weimann, A., Ellervik, C., and Poulsen, H. E. (2018). Iron Induced RNA-Oxidation in the General Population and in Mouse Tissue. Free Radical Biology and Medicine 115, 127-135. doi:10.1016/j. freeradbiomed.2017.11.013

Cejvanovic, V., Kjær, L. K., Mørup Bergholdt, H. K., Henriksen, T., Weimann, A., Ellervik, C., and Poulsen, H. E. (2018). RNA Oxidation and Iron Levels in Patients with Diabetes. Free Radical Biology and Medicine 129, 532-536. doi:10. 1016/j.freeradbiomed.2018.10.420

Chang, Y., Kong, Q., Shan, X., Tian, G., Ilieva, H., Cleveland, D. W., et al. (2008). Messenger RNA Oxidation Occurs Early in Disease Pathogenesis and Promotes Motor Neuron Degeneration in ALS. PLoS One 3, e2849. doi:10.1371/journal. pone.0002849

Chapman, J. R., Taylor, M. R. G., and Boulton, S. J. (2012). Playing the End Game: DNA Double-Strand Break Repair Pathway Choice. Mol. Cell 47, 497-510. doi:10.1016/j.molcel.2012.07.029

Chatterjee, N., and Walker, G. C. (2017). Mechanisms of DNA Damage, Repair, and Mutagenesis. Environ. Mol. Mutagen. 58, 235-263. doi:10.1002/em.22087

Chirkova, A., Erlacher, M. D., Clementi, N., Zywicki, M., Aigner, M., and Polacek, N. (2010). The Role of the Universally Conserved A2450-C2063 Base Pair in the Ribosomal Peptidyl Transferase Center. Nucleic Acids Res. 38, 4844-4855. doi:10.1093/nar/gkq213

Choi, Y. J., Chang, S. J., Gibala, K. S., and Resendiz, M. J. E. (2017). 8-Oxo-7,8dihydroadenine and 8-Oxo-7,8-Dihydroadenosine-Chemistry, Structure, and
Function in RNA and Their Presence in Natural Products and Potential Drug Derivatives. Chem. Eur. J. 23, 6706-6716. doi:10.1002/chem.201605163

Collart, M. A., and Weiss, B. (2020). Ribosome Pausing, a Dangerous Necessity for Co-translational Events. Nucleic Acids Res. 48, 1043-1055. doi:10.1093/nar/ gkz763

Collins, L. V., Hajizadeh, S., Holme, E., Jonsson, I.-M., and Tarkowski, A. (2004). Endogenously Oxidized Mitochondrial DNA Induces In Vivo and In Vitro Inflammatory Responses. J. Leukoc. Biol. 75, 995-1000. doi:10.1189/jlb.0703328

Crean, C., Geacintov, N. E., and Shafirovich, V. (2005). Oxidation of Guanine and 8-Oxo-7,8-Dihydroguanine by Carbonate Radical Anions: Insight from Oxygen-18 Labeling Experiments. Angew. Chem. Int. Ed. 44, 5057-5060. doi:10.1002/anie.200500991

Di, R., and Tumer, N. (2015). Pokeweed Antiviral Protein: its Cytotoxicity Mechanism and Applications in Plant Disease Resistance. Toxins 7, 755-772. doi:10.3390/toxins7030755

Dizdaroglu, M., Jaruga, P., and Rodriguez, H. (2001). Measurement of 8-Hydroxy2'-Deoxyguanosine in DNA by High-Performance Liquid ChromatographyMass Spectrometry: Comparison with Measurement by Gas ChromatographyMass Spectrometry. Nucleic Acids Res. 29, E12. doi:10.1093/nar/29.3.e12

Dizdaroglu, M., Coskun, E., and Jaruga, P. (2017). Repair of Oxidatively Induced DNA Damage by DNA Glycosylases: Mechanisms of Action, Substrate Specificities and Excision Kinetics. Mutat. Research/Reviews Mutat. Res. 771, 99-127. doi:10.1016/j.mrrev.2017.02.001

Endo, Y., Mitsui, K., Motizuki, M., and Tsurugi, K. (1987). The Mechanism of Action of Ricin and Related Toxic Lectins on Eukaryotic Ribosomes. The Site and the Characteristics of the Modification in 28 S Ribosomal RNA Caused by the Toxins. J. Biol. Chem. 262, 5908-5912. doi:10.1016/s0021-9258(18)45660-8

Endo, Y., and Tsurugi, K. (1987). RNA N-Glycosidase Activity of Ricin A-Chain. Mechanism of Action of the Toxic Lectin Ricin on Eukaryotic Ribosomes. J. Biol. Chem. 262, 8128-8130. doi:10.1016/s0021-9258(18)47538-2

Enright, H. U., Miller, W. J., and Hebbel, R. P. (1992). Nucleosomal Histone Protein Protects DNA from Iron-Mediated Damage. Nucl. Acids Res. 20, 3341-3346. doi:10.1093/nar/20.13.3341

Erlacher, M. D., Lang, K., Shankaran, N., Wotzel, B., Huttenhofer, A., Micura, R., et al. (2005). Chemical Engineering of the Peptidyl Transferase Center Reveals an Important Role of the 2'-hydroxyl Group of A2451. Nucleic Acids Res. 33, 1618-1627. doi:10.1093/nar/gki308

Erlacher, M. D., Lang, K., Wotzel, B., Rieder, R., Micura, R., and Polacek, N. (2006). Efficient Ribosomal Peptidyl Transfer Critically Relies on the Presence of the Ribose 2'-OH at A2451 of 23S rRNA. J. Am. Chem. Soc. 128, 4453-4459. doi:10. 1021/ja0588454

Evans, M. D., Dizdaroglu, M., and Cooke, M. S. (2004). Oxidative DNA Damage and Disease: Induction, Repair and Significance. Mutat. Research/Reviews Mutat. Res. 567, 1-61. doi:10.1016/j.mrrev.2003.11.001

Fiala, E. S., Conaway, C. C., and Mathis, J. E. (1989). Oxidative DNA and RNA Damage in the Livers of Sprague-Dawley Rats Treated with the Hepatocarcinogen 2-nitropropane. Cancer Res. 49, 5518-5522.

Floyd, R. A., Watson, J. J., Wong, P. K., Altmiller, D. H., and Rickard, R. C. (1986). Hydroxyl Free Radical Adduct of Deoxyguanosine: Sensitive Detection and Mechanisms of Formation. Free Radic. Res. Commun. 1, 163-172. doi:10.3109/10715768609083148

Frelon, S., Douki, T., Ravanat, J.-L., Pouget, J.-P., Tornabene, C., and Cadet, J. (2000). High-Performance Liquid Chromatography-Tandem Mass Spectrometry Measurement of Radiation-Induced Base Damage to Isolated and Cellular DNA. Chem. Res. Toxicol. 13, 1002-1010. doi:10.1021/tx000085h

Fresco, J. R., and Amosova, O. (2017). Site-Specific Self-Catalyzed DNA Depurination: A Biological Mechanism that Leads to Mutations and Creates Sequence Diversity. Annu. Rev. Biochem. 86, 461-484. doi:10.1146/annurevbiochem-070611-095951

Gandhi, R., Manzoor, M., and Hudak, K. A. (2008). Depurination of Brome Mosaic Virus RNA3 In Vivo Results in Translation-dependent Accelerated Degradation of the Viral RNA. J. Biol. Chem. 283, 32218-32228. doi:10. 1074/jbc.m803785200

García-Muse, T., Aguilera, A., and Loops, R. (2019). R Loops: From Physiological to Pathological Roles. Cell 179, 604-618. doi:10.1016/j.cell.2019.08.055

Goldstein, S., Meyerstein, D., and Czapski, G. (1993). The Fenton Reagents. Free Radic. Biol. Med. 15, 435-445. doi:10.1016/0891-5849(93)90043-t

Gonzalez-Rivera, J. C., Sherman, M. W., Wang, D. S., Chuvalo-Abraham, J. C. L., Hildebrandt Ruiz, L., and Contreras, L. M. (2020). RNA Oxidation in 
Chromatin Modification and DNA-Damage Response Following Exposure to Formaldehyde. Sci. Rep. 10, 16545. doi:10.1038/s41598-020-73376-7

Görg, B., Qvartskhava, N., Keitel, V., Bidmon, H. J., Selbach, O., Schliess, F., et al. (2008). Ammonia Induces RNA Oxidation in Cultured Astrocytes and Brainin Vivo. Hepatology 48, 567-579. doi:10.1002/hep.22345

Gorla, M., and Sepuri, N. B. V. (2014). Perturbation of Apoptosis upon Binding of tRNA to the Heme Domain of Cytochrome C. Apoptosis 19, 259-268. doi:10. 1007/s10495-013-0915-6

Greenberg, M. M. (2016). Reactivity of Nucleic Acid Radicals. Adv. Phys. Org. Chem. 50, 119-202. doi:10.1016/bs.apoc.2016.02.001

Hayakawa, H., Fujikane, A., Ito, R., Matsumoto, M., Nakayama, K. I., and Sekiguchi, M. (2010). Human Proteins that Specifically Bind to 8Oxoguanine-Containing RNA and Their Responses to Oxidative Stress. Biochem. Biophysical Res. Commun. 403, 220-224. doi:10.1016/j.bbrc.2010. 11.011

Hayakawa, H., Kuwano, M., and Sekiguchi, M. (2001). Specific Binding of 8Oxoguanine-Containing RNA to Polynucleotide Phosphorylase Protein. Biochemistry 40, 9977-9982. doi:10.1021/bi010595q

Hayakawa, H., Uchiumi, T., Fukuda, T., Ashizuka, M., Kohno, K., Kuwano, M., et al. (2002). Binding Capacity of Human YB-1 Protein for RNA Containing 8Oxoguanine. Biochemistry 41, 12739-12744. doi:10.1021/bi0201872

Hegazy, Y. A., Fernando, C. M., and Tran, E. J. (2020). The Balancing Act of R-Loop Biology: The Good, the Bad, and the Ugly. J. Biol. Chem. 295, 905-913. doi:10.1074/jbc.rev119.011353

Hipp, M. S., Park, S.-H., and Hartl, F. U. (2014). Proteostasis Impairment in Protein-Misfolding and -aggregation Diseases. Trends Cell Biol. 24, 506-514. doi:10.1016/j.tcb.2014.05.003

Hoernes, T. P., Faserl, K., Juen, M. A., Kremser, J., Gasser, C., Fuchs, E.., et al. (2018a). Translation of Non-standard Codon Nucleotides Reveals Minimal Requirements for Codon-Anticodon Interactions. Nat. Commun. 9, 4865. doi:10.1038/s41467-018-07321-8

Hoernes, T. P., Clementi, N., Juen, M. A., Shi, X., Faserl, K., Willi, J, et al. (2018b). Atomic Mutagenesis of Stop Codon Nucleotides Reveals the Chemical Prerequisites for Release Factor-Mediated Peptide Release. Proc. Natl. Acad. Sci. USA 115, E382-E389. doi:10.1073/pnas.1714554115

Hofer, T., Badouard, C., Bajak, E., Ravanat, J. L., Mattsson, A., and Cotgreave, I. A. (2005). Hydrogen Peroxide Causes Greater Oxidation in Cellular RNA Than in DNA. Biol. Chem. 386, 333-337. doi:10.1515/bc.2005.040

Honda, K., Smith, M. A., Zhu, X., Baus, D., Merrick, W. C., Tartakoff, A. M., et al. (2005). Ribosomal RNA in Alzheimer Disease Is Oxidized by Bound RedoxActive Iron. J. Biol. Chem. 280, 20978-20986. doi:10.1074/jbc.m500526200

Hudak, K. A., Bauman, J. D., and Tumer, N. E. (2002). Pokeweed Antiviral Protein Binds to the Cap Structure of Eukaryotic mRNA and Depurinates the mRNA Downstream of the Cap. RNA 8, 1148-1159. doi:10.1017/ s1355838202026638

Hudak, K. A., Parikh, B. A., Di, R., Baricevic, M., Santana, M., Seskar, M., et al. (2004). Generation of Pokeweed Antiviral Protein Mutations in Saccharomyces cerevisiae: Evidence that Ribosome Depurination Is Not Sufficient for Cytotoxicity. Nucleic Acids Res. 32, 4244-4256. doi:10.1093/nar/gkh757

Hudak, K. A., Wang, P., and Tumer, N. E. (2000). A Novel Mechanism for Inhibition of Translation by Pokeweed Antiviral Protein: Depurination of the Capped RNA Template. RNA 6, 369-380. doi:10.1017/ s1355838200991337

Ikeuchi, K., Izawa, T., and Inada, T. (2018). Recent Progress on the Molecular Mechanism of Quality Controls Induced by Ribosome Stalling. Front. Genet. 9, 743. doi:10.3389/fgene.2018.00743

Ilic, Z., Saxena, A. R., Periasamy, S., and Crawford, D. R. (2019). Control (Native) and Oxidized (DeMP) Mitochondrial RNA Are Proinflammatory Regulators in Human. Free Radic. Biol. Med. 143, 62-69. doi:10.1016/j.freeradbiomed.2019. 07.019

Inamdar, K. V., Pouliot, J. J., Zhou, T., Lees-Miller, S. P., Rasouli-Nia, A., and Povirk, L. F. (2002). Conversion of Phosphoglycolate to Phosphate Termini on $3^{\prime}$ Overhangs of DNA Double Strand Breaks by the Human Tyrosyl-DNA Phosphodiesterase hTdp1. J. Biol. Chem. 277, 27162-27168. doi:10.1074/jbc. m204688200

Ingle, S., Azad, R. N., Jain, S. S., and Tullius, T. D. (2014). Chemical Probing of RNA with the Hydroxyl Radical at Single-Atom Resolution. Nucleic Acids Res. 42, 12758-12767. doi:10.1093/nar/gku934
Ishii, T., Hayakawa, H., Igawa, T., Sekiguchi, T., and Sekiguchi, M. (2018). Specific Binding of PCBP1 to Heavily Oxidized RNA to Induce Cell Death. Proc. Natl. Acad. Sci. USA 115, 6715-6720. doi:10.1073/pnas.1806912115

Ishii, T., Hayakawa, H., Sekiguchi, T., Adachi, N., and Sekiguchi, M. (2015). Role of Auf1 in Elimination of Oxidatively Damaged Messenger RNA in Human Cells. Free Radic. Biol. Med. 79, 109-116. doi:10.1016/j.freeradbiomed.2014. 11.018

Ishii, T., Igawa, T., Hayakawa, H., Fujita, T., Sekiguchi, M., and Nakabeppu, Y. (2020). PCBP1 and PCBP2 Both Bind Heavily Oxidized RNA but Cause Opposing Outcomes, Suppressing or Increasing Apoptosis under Oxidative Conditions. J. Biol. Chem. 295, 12247-12261. doi:10.1074/jbc.ra119.011870

Jacob, K. D., Noren Hooten, N., Trzeciak, A. R., and Evans, M. K. (2013). Markers of Oxidant Stress that Are Clinically Relevant in Aging and Age-Related Disease. Mech. Ageing Develop. 134, 139-157. doi:10.1016/j.mad.2013.02.008

Jones, G. D. D., and O'Neill, P. (1990). The Kinetics of Radiation-Induced Strand Breakage in Polynucleotides in the Presence of Oxygen: a Time-Resolved LightScattering Study. Int. J. Radiat. Biol. 57, 1123-1139. doi:10.1080/ 09553009014551241

Jorgensen, A., Broedbaek, K., Fink-Jensen, A., Knorr, U., Greisen Soendergaard, M., Henriksen, T., et al. (2013). Increased Systemic Oxidatively Generated DNA and RNA Damage in Schizophrenia. Psychiatry Res. 209, 417-423. doi:10.1016/ j.psychres.2013.01.033

Jorgensen, A., Krogh, J., Miskowiak, K., Bolwig, T. G., Kessing, L. V., Fink-Jensen, A., et al. (2013). Systemic Oxidatively Generated DNA/RNA Damage in Clinical Depression: Associations to Symptom Severity and Response to Electroconvulsive Therapy. J. Affective Disord. 149, 355-362. doi:10.1016/j. jad.2013.02.011

Joyner, J. C., Keuper, K. D., and Cowan, J. A. (2013). Analysis of RNA Cleavage by MALDI-TOF Mass Spectrometry. Nucleic Acids Res. 41, e2. doi:10.1093/nar/ gks811

Joyner, J. C., Keuper, K. D., and Cowan, J. A. (2013). Kinetics and Mechanisms of Oxidative Cleavage of HIV RRE RNA by Rev-Coupled Transition MetalChelates. Chem. Sci. 4, 1707-1718. doi:10.1039/c3sc22135k

Kim, H. J., Yoon, S.-H., Ryu, H.-O., Yoon, B.-H., Choi, S., Ye, S.-K., et al. (2007). 8oxo-7,8-dihydroguanosine Triphosphate(8-oxoGTP) Down-Regulates Respiratory Burst of Neutrophils by Antagonizing GTP toward Rac, a Small GTP Binding Protein. Free Radic. Res. 41, 655-662. doi:10.1080/ 10715760701250270

Koga, Y., Taniguchi, Y., and Sasaki, S. (2013). Synthesis of the Oligoribonucleotides Incorporating 8-Oxo-Guanosine and Evaluation of Their Base Pairing Properties. Nucleosides, Nucleotides and Nucleic Acids 32, 124-136. doi:10. 1080/15257770.2013.767461

Kuo, C.-F., McRee, D. E., Cunningham, R. P., and Tainer, J. A. (1993). Purification, Crystallization and Space Group Determination of DNA Repair Enzyme Exonuclease III from E. coli. J. Mol. Biol. 229, 239-242. doi:10.1006/jmbi. 1993.1021

Küpfer, P. A., Crey-Desbiolles, C., and Leumann, C. J. (2007). Trans-lesion Synthesis and RNaseH Activity by Reverse Transcriptases on a True Abasic RNA Template. Nucleic Acids Res. 35, 6846-6853. doi:10.1093/nar/gkm767

Küpfer, P. A., and Leumann, C. J. (2007a). Photochemically Induced RNA and DNA Abasic Sites. Nucleosides, Nucleotides \& Nucleic Acids 26, 1177-1180. doi:10.1080/15257770701527711

Küpfer, P. A., and Leumann, C. J. (2007b). The Chemical Stability of Abasic RNA Compared to Abasic DNA. Nucleic Acids Res. 35, 58-68. doi:10.1093/nar/ gkl948

Lanz, M. C., Dibitetto, D., and Smolka, M. B. (2019). DNA Damage Kinase Signaling: Checkpoint and Repair at 30 Years. EMBO J. 38, e101801. doi:10. 15252/embj.2019101801

Larsen, E. L., Weimann, A., and Poulsen, H. E. (2019). Interventions Targeted at Oxidatively Generated Modifications of Nucleic Acids Focused on Urine and Plasma Markers. Free Radic. Biol. Med. 145, 256-283. doi:10.1016/j. freeradbiomed.2019.09.030

Lee, J.-K., Ko, S.-H., Ye, S.-K., and Chung, M.-H. (2013). 8-Oxo-2'-deoxyguanosine Ameliorates UVB-Induced Skin Damage in Hairless Mice by Scavenging Reactive Oxygen Species and Inhibiting MMP Expression. J. Dermatol. Sci. 70, 49-57. doi:10.1016/j.jdermsci.2013.01.010

Lemaire, D. G. E., Bothe, E., and Schulte-Frohlinde, D. (1984). Yields of RadiationInduced Main Chain Scission of Poly U in Aqueous Solution: Strand Break 
Formation via Base Radicals. Int. J. Radiat. Biol. Relat. Stud. Phys. Chem. Med. 45, 351-358. doi:10.1080/09553008414550491

Lin, C., and Miles, W. O. (2019). Beyond CLIP: Advances and Opportunities to Measure RBP-RNA and RNA-RNA Interactions. Nucleic Acids Res. 47, 5490-5501. doi:10.1093/nar/gkz295

Lindahl, T. (1993). Instability and Decay of the Primary Structure of DNA. Nature 362, 709-715. doi:10.1038/362709a0

Liu, Y., Rodriguez, Y., Ross, R. L., Zhao, R., Watts, J. A., Grunseich, C., et al. (2020). RNA Abasic Sites in Yeast and Human Cells. Proc. Natl. Acad. Sci. USA 117, 20689-20695. doi:10.1073/pnas.2011511117

Margolin, Y., Shafirovich, V., Geacintov, N. E., DeMott, M. S., and Dedon, P. C. (2008). DNA Sequence Context as a Determinant of the Quantity and Chemistry of Guanine Oxidation Produced by Hydroxyl Radicals and OneElectron Oxidants. J. Biol. Chem. 283, 35569-35578. doi:10.1074/jbc. m806809200

Mei, Y., Yong, J., Liu, H., Shi, Y., Meinkoth, J., Dreyfuss, G., et al. (2010). tRNA Binds to Cytochrome C and Inhibits Caspase Activation. Mol. Cell 37, 668-678. doi:10.1016/j.molcel.2010.01.023

Mirzaei, H., and Regnier, F. (2006). Protein-RNA Cross-Linking in the Ribosomes of Yeast under Oxidative Stress. J. Proteome Res. 5, 3249-3259. doi:10.1021/ pr0603371

Montanaro, L., Sperti, S., Mattioli, A., Testoni, G., and Stirpe, F. (1975). Inhibition by Ricin of Protein Synthesis In Vitro. Inhibition of the Binding of Elongation Factor 2 and of Adenosine Diphosphate-Ribosylated Elongation Factor 2 to Ribosomes. Biochem. J. 146, 127-131. doi:10. $1042 / \mathrm{bj} 1460127$

Nilov, D. I., Komarov, D. Y., Panov, M. S., Karabaeva, K. E., Mereshchenko, A. S., Tarnovsky, A. N., et al. (2013). Oxidation of Adenosine and Inosine: the Chemistry of 8-Oxo-7,8-Dihydropurines, Purine Iminoquinones, and Purine Quinones as Observed by Ultrafast Spectroscopy. J. Am. Chem. Soc. 135, 3423-3438. doi:10.1021/ja3068148

Nunomura, A., Perry, G., Pappolla, M. A., Wade, R., Hirai, K., Chiba, S., et al. (1999). RNA Oxidation Is a Prominent Feature of Vulnerable Neurons in Alzheimer's Disease. J. Neurosci. 19, 1959-1964. doi:10.1523/jneurosci.19-0601959.1999

Payne, N. C., Geissler, A., Button, A., Sasuclark, A. R., Schroll, A. L., Ruggles, E. L., et al. (2017). Comparison of the Redox Chemistry of Sulfur- and SeleniumContaining Analogs of Uracil. Free Radic. Biol. Med. 104, 249-261. doi:10.1016/ j.freeradbiomed.2017.01.028

Poulsen, H. E., Specht, E., Broedbaek, K., Henriksen, T., Ellervik, C., MandrupPoulsen, T., et al. (2012). RNA Modifications by Oxidation: a Novel Disease Mechanism?. Free Radic. Biol. Med. 52, 1353-1361. doi:10.1016/j. freeradbiomed.2012.01.009

Povirk, L. F., Zhou, T., Zhou, R., Cowan, M. J., and Yannone, S. M. (2007). Processing of $3^{\prime}$-Phosphoglycolate-Terminated DNA Double Strand Breaks by Artemis Nuclease. J. Biol. Chem. 282, 3547-3558. doi:10.1074/jbc. m607745200

Preiss, J., Berg, P., Ofengand, E. J., Bergmann, F. H., and Dieckmann, M. (1959). The Chemical Nature of the Rna-Amino Acid Compound Formed by Amino Acid-Activating Enzymes. Proc. Natl. Acad. Sci. 45, 319-328. doi:10.1073/pnas. 45.3.319

Rao, Y. S. P., and Cherayil, J. D. (1974). Studies on Chemical Modification of Thionucleosides in the Transfer Ribonucleic Acid of Escherichia coli. Biochem. J. 143, 285-294. doi:10.1042/bj1430285

Rhee, S. G. (2006). CELL SIGNALING: H2O2, a Necessary Evil for Cell Signaling. Science 312, 1882-1883. doi:10.1126/science.1130481

Saxena, A. R., Gao, L. Y., Srivatsa, S., Bobersky, E. Z., Periasamy, S., Hunt, D. T., et al. (2017). Oxidized and Degraded Mitochondrial Polynucleotides (DeMPs), Especially RNA, Are Potent Immunogenic Regulators in Primary Mouse Macrophages. Free Radic. Biol. Med. 104, 371-379. doi:10.1016/j. freeradbiomed.2017.02.009

Schrode, P., Huter, P., Clementi, N., and Erlacher, M. (2017). Atomic Mutagenesis at the Ribosomal Decoding Site. RNA Biol. 14, 104-112. doi:10.1080/15476286. 2016.1256535

Sengupta, S., Wang, H., Yang, C., Szczesny, B., Hegde, M. L., and Mitra, S. (2020). Ligand-induced Gene Activation Is Associated with Oxidative Genome Damage Whose Repair Is Required for Transcription. Proc. Natl. Acad. Sci. USA 117, 22183-22192. doi:10.1073/pnas.1919445117
Shan, X., Chang, Y., and Glenn Lin, C. 1. (2007). Messenger RNA Oxidation Is an Early Event Preceding Cell Death and Causes Reduced Protein Expression. FASEB J. 21, 2753-2764. doi:10.1096/fj.07-8200com

Shan, X., and Lin, C.-1. G. (2006). Quantification of Oxidized RNAs in Alzheimer's Disease. Neurobiol. Aging 27, 657-662. doi:10.1016/j.neurobiolaging.2005. 03.022

Shan, X., Tashiro, H., and Lin, C.-1. G. (2003). The Identification and Characterization of Oxidized RNAs in Alzheimer's Disease. J. Neurosci. 23, 4913-4921. doi:10.1523/jneurosci.23-12-04913.2003

Sharma, D., Zagore, L. L., Brister, M. M., Ye, X., Crespo-Hernández, C. E., Licatalosi, D. D., et al. (2021). The Kinetic Landscape of an RNA-Binding Protein in Cells. Nature 591, 152-156. doi:10.1038/s41586-021-03222-x

Shi, X., Khade, P. K., Sanbonmatsu, K. Y., and Joseph, S. (2012). Functional Role of the Sarcin-Ricin Loop of the 23S rRNA in the Elongation Cycle of Protein Synthesis. J. Mol. Biol. 419, 125-138. doi:10.1016/j.jmb.2012.03.016

Shigenaga, M. K., Gimeno, C. J., and Ames, B. N. (1989). Urinary 8-Hydroxy-2'Deoxyguanosine as a Biological Marker of In Vivo Oxidative DNA Damage. Proc. Natl. Acad. Sci. 86, 9697-9701. doi:10.1073/pnas.86.24.9697

Shimada, K., Crother, T. R., Karlin, J., Dagvadorj, J., Chiba, N., Chen, S., et al. (2012). Oxidized Mitochondrial DNA Activates the NLRP3 Inflammasome during Apoptosis. Immunity 36, 401-414. doi:10.1016/j.immuni.2012.01.009

Sierant, M., Kulik, K., Sochacka, E., Szewczyk, R., Sobczak, M., and Nawrot, B. (2018). Cytochrome C Catalyzes the Hydrogen Peroxide-Assisted Oxidative Desulfuration of 2-Thiouridines in Transfer RNAs. Chembiochem 19, 687-695. doi:10.1002/cbic.201700692

Simms, C. L., Kim, K. Q., Yan, L. L., Qiu, J., and Zaher, H. S. (2018). Interactions between the mRNA and Rps3/uS3 at the Entry Tunnel of the Ribosomal Small Subunit Are Important for No-Go Decay. Plos Genet. 14, e1007818. doi:10. 1371/journal.pgen.1007818

Simms, C. L., Thomas, E. N., and Zaher, H. S. (2017). Ribosome-based Quality Control of mRNA and Nascent Peptides. Wiley Interdiscip. Rev. RNA 8, e1366. doi:10.1002/wrna.1366

Simms, C. L., Hudson, B. H., Mosior, J. W., Rangwala, A. S., and Zaher, H. S. (2014). An Active Role for the Ribosome in Determining the Fate of Oxidized mRNA. Cel Rep. 9, 1256-1264. doi:10.1016/j.celrep.2014.10.042

Simms, C. L., Yan, L. L., and Zaher, H. S. (2017b). Ribosome Collision Is Critical for Quality Control during No-Go Decay. Mol. Cel 68, 361-373. doi:10.1016/j. molcel.2017.08.019

Sochacka, E., Bartos, P., Kraszewska, K., and Nawrot, B. (2013). Desulfuration of 2thiouridine with Hydrogen Peroxide in the Physiological pH Range 6.6-7.6 Is $\mathrm{pH}$-dependent and Results in Two Distinct Products. Bioorg. Med. Chem. Lett. 23, 5803-5805. doi:10.1016/j.bmcl.2013.08.114

Sochacka, E., Kraszewska, K., Sochacki, M., Sobczak, M., Janicka, M., and Nawrot, B. (2011). The 2-thiouridine Unit in the RNA Strand Is Desulfured Predominantly to 4-pyrimidinone Nucleoside under In Vitro Oxidative Stress Conditions. Chem. Commun. 47, 4914-4916. doi:10.1039/c1cc10973a

Sochacka, E., Szczepanowski, R. H., Cypryk, M., Sobczak, M., Janicka, M., Kraszewska, K., et al. (2015). 2-Thiouracil Deprived of Thiocarbonyl Function Preferentially Base Pairs with Guanine rather Than Adenine in RNA and DNA Duplexes. Nucleic Acids Res. 43, 2499-2512. doi:10.1093/ nar/gkv109

Stadtman, E. R., and Berlett, B. S. (1997). Reactive Oxygen-Mediated Protein Oxidation in Aging and Disease. Chem. Res. Toxicol. 10, 485-494. doi:10.1021/ tx960133r

Steenkcn, S., and Jovanovic, S. V. (1997). How Easily Oxidizable Is DNA? OneElectron Reduction Potentials of Adenosine and Guanosine Radicals in Aqueous Solution. J. Am. Chem. Soc. 119, 2. . doi:10.1021/ja962255b

Taddei, F., Hayakawa, H., Bouton, M.-F., Cirinesi, A.-M., Matic, I., Sekiguchi, M., et al. (1997). Counteraction by MutT Protein of Transcriptional Errors Caused by Oxidative Damage. Science 278, 128-130. doi:10.1126/science.278.5335.128

Tanaka, M., Chock, P. B., and Stadtman, E. R. (2007). Oxidized Messenger RNA Induces Translation Errors. Proc. Natl. Acad. Sci. 104, 66-71. doi:10.1073/pnas. 0609737104

Tanaka, M., Han, S., Küpfer, P. A., Leumann, C. J., and Sonntag, W. E. (2011a). Quantification of Oxidized Levels of Specific RNA Species Using an Aldehyde Reactive Probe. Anal. Biochem. 417, 142-148. doi:10.1016/j.ab.2011.05.038

Tanaka, M., Jaruga, P., Küpfer, P. A., Leumann, C. J., Dizdaroglu, M., Sonntag, W. E., et al. (2012). RNA Oxidation Catalyzed by Cytochrome C Leads to its 
Depurination and Cross-Linking, Which May Facilitate Cytochrome C Release from Mitochondria. Free Radic. Biol. Med. 53, 854-862. doi:10.1016/j. freeradbiomed.2012.05.044

Tanaka, M., Song, H., Küpfer, P. A., Leumann, C. J., and Sonntag, W. E. (2011b). An Assay for RNA Oxidation Induced Abasic Sites Using the Aldehyde Reactive Probe. Free Radic. Res. 45, 237-247. doi:10.3109/10715762.2010.535529

Thannickal, V. J., and Fanburg, B. L. (2000). Reactive Oxygen Species in Cell Signaling. Am. J. Physiology-Lung Cell Mol. Physiol. 279, L1005-L1028. doi:10. 1152/ajplung.2000.279.6.11005

Thomas, E. N., Simms, C. L., Keedy, H. E., and Zaher, H. S. (2019). Insights into the Base-Pairing Preferences of 8-oxoguanosine on the Ribosome. Nucleic Acids Res. 47, 9857-9870. doi:10.1093/nar/gkz701

Tomaszewska-Antczak, A., Guga, P., Nawrot, B., and Pratviel, G. (2015). Guanosine in a Single Stranded Region of Anticodon Stem-Loop tRNA Models Is Prone to Oxidatively Generated Damage Resulting in Dehydroguanidinohydantoin and Spiroiminodihydantoin Lesions. Chem. Eur. J. 21, 6381-6385. doi:10.1002/chem.201406409

Tomlinson, J. A., Walker, V. M., Flewett, T. H., and Barclay, G. R. (1974). The Inhibition of Infection by Cucumber Mosaic Virus and Influenza Virus by Extracts from Phytolacca Americana. J. Gen. Virol. 22, 225-232. doi:10.1099/ 0022-1317-22-2-225

Van Nostrand, E. L., Pratt, G. A., Shishkin, A. A., Gelboin-Burkhart, C., Fang, M. Y., Sundararaman, B., et al. (2016). Robust Transcriptome-wide Discovery of RNA-Binding Protein Binding Sites with Enhanced CLIP (eCLIP). Nat. Methods 13, 508-514. doi:10.1038/nmeth.3810

Vascotto, C., Fantini, D., Romanello, M., Cesaratto, L., Deganuto, M., Leonardi, A., et al. (2009). APE1/Ref-1 Interacts with NPM1 within Nucleoli and Plays a Role in the rRNA Quality Control Process. Mcb 29, 1834-1854. doi:10.1128/mcb. 01337-08

Walker, R. T., and RajBhandary, U. L. (1972). Studies on Polynucleotides. J. Biol. Chem. 247, 4879-4892. doi:10.1016/s0021-9258(19)44993-4

Wamer, W. G., and Wei, R. R. (1997). In vitro photooxidation of Nucleic Acids by Ultraviolet A Radiation. Photochem. Photobiol. 65, 560-563. doi:10.1111/j. 1751-1097.1997.tb08605.x

Wang, I. X., Grunseich, C., Fox, J., Burdick, J., Zhu, Z., Ravazian, N., et al. (2018). Human Proteins that Interact with RNA/DNA Hybrids. Genome Res. 28, 1405-1414. doi:10.1101/gr.237362.118

Wang, J.-X., Gao, J., Ding, S.-L., Wang, K., Jiao, J.-Q., Wang, Y., et al. (2015). Oxidative Modification of miR-184 Enables it to Target Bcl-xL and Bcl-W. Mol. Cell 59, 50-61. doi:10.1016/j.molcel.2015.05.003

Wardman, P., and Candeias, L. P. (1996). Fenton Chemistry: an Introduction. Radiat. Res. 145, 523-531. doi:10.2307/3579270

Weidner, A. M., Bradley, M. A., Beckett, T. L., Niedowicz, D. M., Dowling, A. L., Matveev, S. V., et al. (2011). RNA Oxidation Adducts 8-OHG and 8-OHA Change with Abeta42 Levels in Late-Stage Alzheimer's Disease. PLoS One 6, e24930. doi:10.1371/journal.pone.0024930

Weimann, A., Belling, D., and Poulsen, H. E. (2002). Quantification of 8-OxoGuanine and Guanine as the Nucleobase, Nucleoside and Deoxynucleoside Forms in Human Urine by High-Performance Liquid ChromatographyElectrospray Tandem Mass Spectrometry. Nucleic Acids Res. 30, E7. doi:10. 1093/nar/30.2.e7

White, B., Tarun, M. C., Gathergood, N., Rusling, J. F., and Smyth, M. R. (2005). Oxidised Guanidinohydantoin (Ghox) and Spiroiminodihydantoin (Sp) Are Major Products of Iron- and Copper-Mediated 8-Oxo-7,8-Dihydroguanine and
8-Oxo-7,8-Dihydro-2'-Deoxyguanosine Oxidation. Mol. Biosyst. 1, 373-381. doi:10.1039/b511756a

Willi, J., Küpfer, P., Evéquoz, D., Fernandez, G., Katz, A., Leumann, C., et al. (2018). Oxidative Stress Damages rRNA inside the Ribosome and Differentially Affects the Catalytic Center. Nucleic Acids Res. 46, 1945-1957. doi:10.1093/nar/ gkx1308

Wu, J., and Li, Z. (2008). Human Polynucleotide Phosphorylase Reduces Oxidative RNA Damage and Protects HeLa Cell against Oxidative Stress. Biochem. Biophysical Res. Commun. 372, 288-292. doi:10.1016/j.bbrc.2008.05.058

Wyatt, S. D., and Shepherd, R. J. (1969). Isolation and Characterization of a Virus Inhibitor from Phytolacca Americana. Phytopathology 59, 1787-1794 .

Wyngaarden, J. B., and Dunn, J. T. (1957). 8-Hydroxyadenine as the Intermediate in the Oxidation of Adenine to 2,8-dihydroxyadenine by Xanthine Oxidase. Arch. Biochem. Biophys. 70, 150-156. doi:10.1016/0003-9861(57)90088-7

Yan, L. L., Simms, C. L., McLoughlin, F., Vierstra, R. D., and Zaher, H. S. (2019). Oxidation and Alkylation Stresses Activate Ribosome-Quality Control. Nat. Commun. 10, 5611. doi:10.1038/s41467-019-13579-3

Yan, L. L., and Zaher, H. S. (2019). How Do Cells Cope with RNA Damage and its Consequences?. J. Biol. Chem. 294, 15158-15171. doi:10.1074/jbc.rev119. 006513

Yanagawa, H., Ogawa, Y., and Ueno, M. (1992). Redox Ribonucleosides. Isolation and Characterization of 5-hydroxyuridine, 8-hydroxyguanosine, and 8hydroxyadenosine from Torula Yeast RNA. J. Biol. Chem. 267, 13320-13326. doi:10.1016/s0021-9258(18)42213-2

Yanagawa, H., Ogawa, Y., Ueno, M., Sasaki, K., and Sato, T. (1990). A Novel Minimum Ribozyme with Oxidoreduction Activity. Biochemistry 29, 10585-10589. doi:10.1021/bi00499a002

Yin, V., Shaw, G. S., and Konermann, L. (2017). Cytochrome C as a Peroxidase: Activation of the Precatalytic Native State by H2O2-Induced Covalent Modifications. J. Am. Chem. Soc. 139, 15701-15709. doi:10.1021/jacs. $7 \mathrm{~b} 07106$

Yoon, S.-H., Hyun, J.-W., Choi, J., Choi, E.-Y., Kim, H.-J., Lee, S.-J., et al. (2005). In vitro evidence for the Recognition of 8-oxoGTP by Ras, a Small GTP-Binding Protein. Biochem. Biophysical Res. Commun. 327, 342-348. doi:10.1016/j.bbrc. 2004.12.013

Zhang, J., Perry, G., Smith, M. A., Robertson, D., Olson, S. J., Graham, D. G., et al. (1999). Parkinson's Disease Is Associated with Oxidative Damage to Cytoplasmic DNA and RNA in Substantia Nigra Neurons. Am. J. Pathol. 154, 1423-1429. doi:10.1016/s0002-9440(10)65396-5

Zinskie, J. A., Ghosh, A., Trainor, B. M., Shedlovskiy, D., Pestov, D. G., and Shcherbik, N. (2018). Iron-dependent Cleavage of Ribosomal RNA during Oxidative Stress in the Yeast Saccharomyces cerevisiae. J. Biol. Chem. 293, 14237-14248. doi:10.1074/jbc.ra118.004174

Conflict of Interest: The authors declare that the research was conducted in the absence of any commercial or financial relationships that could be construed as a potential conflict of interest.

Copyright $(\odot 2021$ Tanaka and Chock. This is an open-access article distributed under the terms of the Creative Commons Attribution License (CC BY). The use, distribution or reproduction in other forums is permitted, provided the original author(s) and the copyright owner(s) are credited and that the original publication in this journal is cited, in accordance with accepted academic practice. No use, distribution or reproduction is permitted which does not comply with these terms. 